\title{
Sistem Otentikasi Login dengan Single Sign-On untuk Mengakses Banyak Sistem
}

\author{
THETA DINNARWATY PUTRI ${ }^{1}$, WINARNO SUGENG ${ }^{2}$, RESI KATRI ${ }^{3}$ \\ 1,2,3Program Studi Informatika Institut Teknologi Nasional Bandung \\ Email : theta@itenas.ac.id
}

Received 31 Juli 2019 | Revised 20 Agustus 2019 | Accepted 10 September 2019

\begin{abstract}
ABSTRAK
SSO memungkinkan mengakses beberapa aplikasi dengan menggunakan satu akun melalui integrasi LDAP sebagai menajemen pengguna. Pada penerapan SSO ini digunakan layanan explicite FTPS sebagai layanan pertukaran dan penyimpanan data. Explicite FTPS merupakan pengembangan layanan FTP dengan fasilitas SSL. Protocol keamanan pada SSL pada saat pengiriman data bersifat privat antara klien dan server, sehingga pertukaran data menjadi aman karena sudah terenkripsi. Dalam sebuah jaringan, tolak ukur tingkat keamanan aplikasi yang saling terintegrasi tidak hanya dari otentikasi, tetapi juga otorisasi. Pada sistem ini menerapkan metode otentikasi dan otorisasi dengan fasilitas RADIUS sebagai protokol yang memberi izin akses setelah proses otentikasi dengan parameter akses diterima atau akses ditolak, sehingga tujuan akhir sistem ini akan menjadi efisien dan terlindungi.
\end{abstract}

Kata kunci: SSO, SSL, Explicite FTPS, RADIUS, LDAP

\begin{abstract}
SSO allows accessing multiple applications using a single account through the integration of LDAP as user management. In the implementation of this SSO used explicite FTPS as a service of exchange and data storage. Explicite FTPS is an FTP service development with SSL facility. The security protocol on SSL when sending data is private to clients and servers, so the exchange of data to be safe because it is encrypted. In a network, the benchmark application security level is integrated not only from authentication, but also authorization. This system applies authentication and authorization methods with RADIUS facility as that grants access permissions after authentication with access-accept or access-reject access, so the final goal this system will be efficient and protected.
\end{abstract}

Keywords: SSO, SSL, Explicite FTPS, RADIUS, LDAP 


\section{PENDAHULUAN}

Beberapa proses otentikasi pengguna umumnya menggunakan banyak akun untuk mengakses beberapa layanan aplikasi, yang tentunya akan mempersulit pengguna dalam mengingat akun untuk masing-masing aplikasi. Mekanisme SSO (Single Sign-On) dapat membantu pengguna dalam proses otentikasi (Aminuddin, 2014). Dengan menerapkan cara tersebut pengguna saat mengakses banyak aplikasi yang sudah terintegrasi cukup hanya satu kali login. Teknik tersebut diperoleh dengan memanfaatkan LDAP (Lightweight Directory Access Protocol) untuk memanajemen pengguna dan CAS (Central Authentication Service) sebagai pusat otentikasi. Penerapan dari SSO dapat diintegrasikan ke beberapa layanan jaringan seperti web service, mail service, dan explicite FTPS (File Transfer Protocol explicite secure) service.

Pada dasarnya explicite FTPS merupakan layanan file sever yang digunakan dalam penyimpanan arsip atau pertukaran data. Kondisi normal proses pengiriman data dari klien ke server belum terenkripsi, sehingga diperlukan keamanan dari paket data tersebut untuk menunjang dalam proses perizinan akses (Rusmana, 2016). Proses enkripsi data dengan Protokol SSL (Secure Socket Layer) digunakan dalam hal proteksi paket data (Amiruddin, 2018). Kebutuhan autentikasi, otorisasi dan pendaftaran akun pengguna secara terpusat saat mengakses jaringan digunakan RADIUS (Remote Authentication Dial-In User Service) (Prajna, 2014) sehingga mampu membantu menyederhanakan proses login.

Protokol keamanan SSL saat pengiriman data antara klien dan server bersifat privat. Sedangkan RADIUS merupakan protokol yang memberi izin akses setelah proses otentikasi dengan parameter akses diterima (access-accept) atau akses ditolak (access-reject) (Agustian, 2013). Dengan menerapkan SSL dan RADIUS pada FTP (File Transfer Protocol) sistem akan lebih terproteksi dari usaha pencurian data dari pihak ketiga (Fernando, 2010). Dalam proses pembuktian keamanan yang menggunakan protocol SSL digunakan proses pengujian sniffing dengan cara menganalisa paket datanya (D.C Pramudita, 2014). Pada pengujian sniffing dilakukan analisa paket data dengan cara penyadapan pada jaringan yang diuji dalam memperoleh data atau informasi saat proses pertukaran data dari klien ke server (Juliharta, 2015) dari pengujian ini akan dibuktikan keberhasilan dari enkripsi data login.

\section{METODE PENELITIAN}

Dalam pengembangan perangkat lunak (software development process) dalam penelitian ini digunakan model prototipe seperti terlihat pada Gambar 1 sebagai penerapan struktur pada pengembangan perangkat lunak (software) dan sebagai panduan untuk menyukseskan proyek pengembangan sistem melalui tahapan-tahapan dari pengembangan perangkat lunak menggunakan model prototipe.

Pengembangan perangkat lunak menggunakan model prototipe dengan dasar satu metode siklus hidup sistem yang didasarkan pada konsep model bekerja, bertujuan pengembangan model menjadi sistem final. Artinya sistem akan dikembangkan lebih cepat dari pada metode tradisional dan biayanya menjadi lebih rendah. Sebagai pengenalan dari metode tersebut adalah baik dari sisi pengembang dan dari sisi pelanggan mampu melihat sekaligus melakukan pengerjaan dimulai dari bagian awal hingga akhir proses pengembangan. 


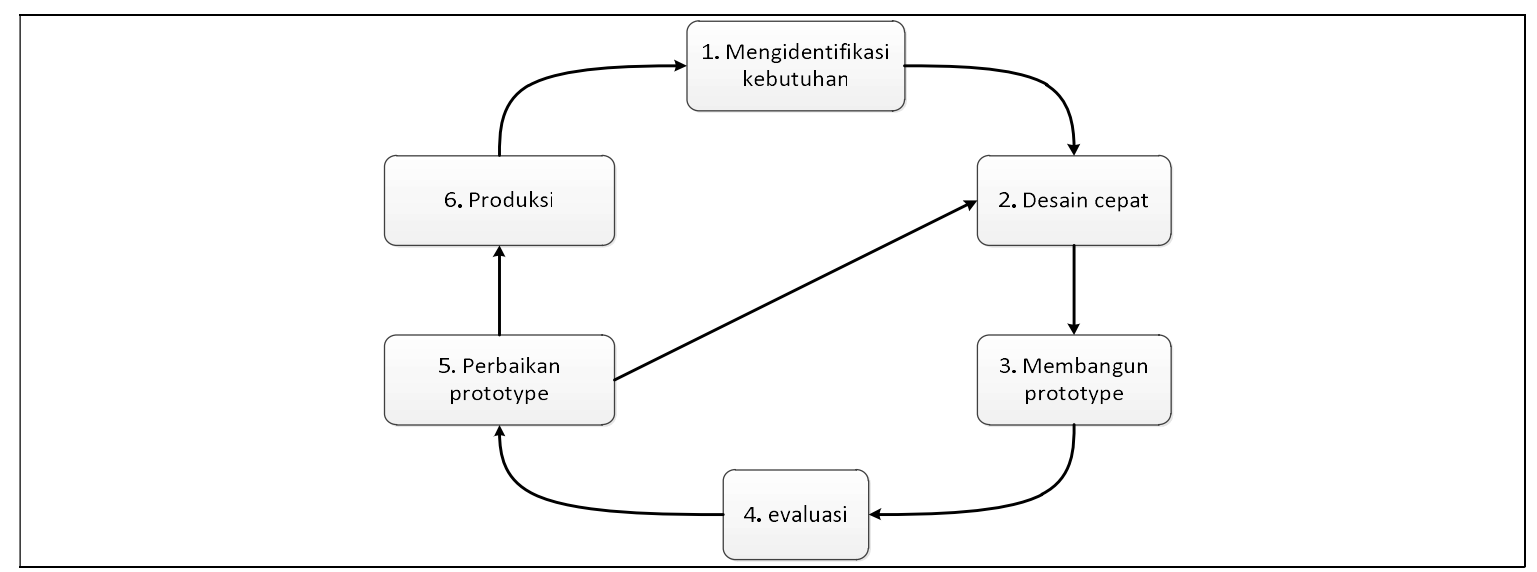

Gambar 1. Model Prototipe (sumber:careerride.com, 2018)

Setelah melalui tahap awal yaitu melakukan identifikasi berkaitan dengan perangkat lunak dan semua kebutuhan sistem yang akan dibuat, tahap dilanjutkan ke tahap desain cepat atau rancangan dasar. Rancangan dasar dapat dilihat melalui Gambar 2 dari blok diagram umum. Tahapan penelitian dilanjutkan sesuai proses mengikuti metode prototipe, hanya proses produksi tidak dilakukan dikarenakan diperlukan pengujian lanjutan lebih dalam dan kompleks, dalam hala ini akan dilakukan penelitian lanjutkan tingkat hibah penelitian.

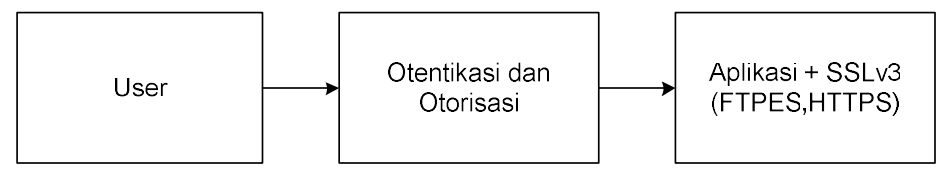

\section{Gambar 2. Blok Diagram Umum}

Sebagaimana yang telah disampiakan sebelumnya diperlukan proses otentikasi dan otorisasi dari layanan akun yang menggunakan modul protokol keamanan untuk masuk dalam banyak sistem secara sekaligus melalui satu pintu. Penerapan sebuah layanan dengan atau tanpa protokol keamanan SSL memungkinkan pemusatan otentikasi dan otorisasi dalam sebuah jaringan SSO yang terintegrasi pada RADIUS dan LDAP, sebagai akun tunggal untuk mengakses beberapa aplikasi.

Berdasarkan permasalahan otentikasi, otorisasi dan pengamanan paket data dari proses sniffing yang bertugas sebagai penganalisa paket data pada pertukaran dan penyimpanan data. Protokol SSL yang digunakan untuk proses pertukaran dan penyimpanan data menjadi terproteksi pada explicite FTPS, RADIUS, LDAP, dengan otentikasi dan otorisasi terpusat pada sistem SSO yang dibangun. Tahapan proses yang dilakukan adalah dengan menerapkan konfigurasi modul pam_RADIUS pada integrasi RADIUS (freeradius) ke LDAP (/dapadmin) sebagai otentikasi dan otorisasi layanan explicite FTPS. Selanjutnya menerapkan konfigurasi modul SSL pada layanan pihak ketiga, yaitu aplikasi proFTPd dengan merubah parameter layanan menjadi explicite secure seperti FTPES dan HTTPS. Dengan cara ini memungkinkan peningkatan proses pengamanan paket data dari usaha proses sniffing pihak penyusup. Tahapan kemudian adalah memfasilitasi layanan otentikasi akun tunggal terpusat SSO dengan memanfaatkan integrasi CAS dan LDAP. Dari penerapan metode otentikasi dan otorisasi, menjadikan sistem menjadi terproteksi dan menajemen akun pengguna menjadi sederhana. 


\subsection{Mekanisme sistem tanpa dan dengan Secure Socket Layer pada pemusatan otentikasi FTPES}

Pada penelitian ini aplikasi yang digunakan adalah FTP server dengan tolak ukur perbandingan sistem tanpa dan dengan menggunakan SSL. Pada Gambar 3 diilustrasikan bahwa FTP server yang merupakan aplikasi utama dalam penelitian ini merupakan aplikasi yang terdiri dari dua jenis otentikasi yaitu dengan Anonymous Authentication dan User Authentication. Anonymous authentication merupakan proses mengenali identitas pengguna secara acak atau tanpa menggunakan pengenal seperti akun dari pengguna, sedangkan User Authentication dapat dilakukan dengan menggunakan otentikasi langsung dari root server yang dibangun pada sistem operasi itu sendiri atau dengan menggunakan modul PAM (Pluggable Authentication Module) seperti mod_RADIUS dan mod_LDAP, sehingga penerapan otentikasi dan otorisasi terpusat pada LDAP dan RADIUS dapat dilakukan. Otentikasi dan otorisasi merupakan bagian penting dari aspek keamanan suatu sistem, tetapi layanan yang terhubung pada aspek keamanan tersebut juga harus diproteksi.

Dalam penelitian ini dilakukan proteksi untuk mencegah pengambilan paket data secara ilegal, dengan menggunakan mod_SSL/TLS, yang merupakan modul dari Socket Secure Layer, sehingga pada otentikasi layanan FTP tanpa SSL seperti diilustrasikan pada Gambar 3 (a) tidak akan melakukan proses digital certicate request pada openss/ sebagai penyedia protokol keamanan, sedangkan pada otentikasi layanan FTP dengan SSL seperti diilustrasikan pada Gambar 3 (b) akan melakukan proses pembuatan digital certicate yang akan disimpan dalam format cert pada server dimana openssl digunakan.

Hasil dari Gambar 3 (b), merupakan komunikasi FTPES, RADIUS, dan LDAP akan dihubungkan dengan web service menggunakan Wordpress, dan proses ini disebut pengembangan tahap satu, yang selanjutnya akan dihubungkan pada metode Central Authentication Service yang disebut Single Sign On sebagai proses pengembangan tahap kedua yang akan dijelaskan selanjutnya.

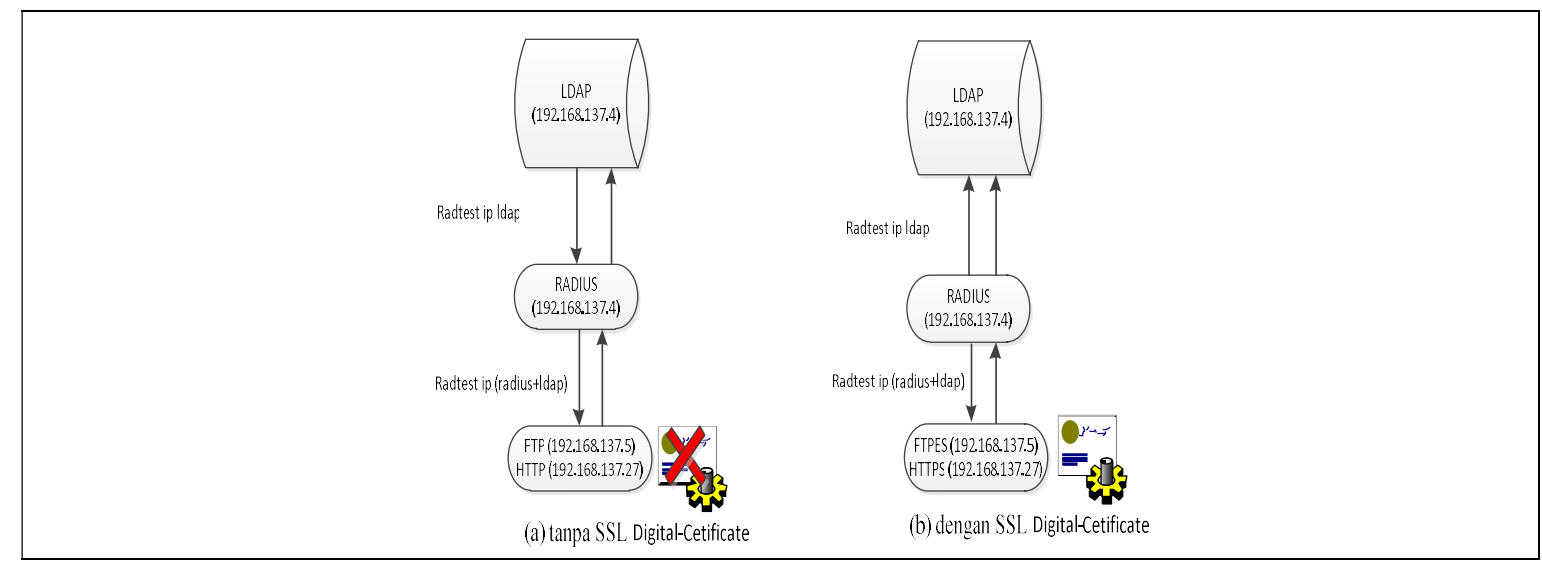

Gambar 3. Arsitektur dengan atau tanpa Sistem SSL

\subsection{Mekanisme sistem tanda dan dengan Single Sign On}

Pada penelitian ini sistem yang belum terintegrasi Single Sing On akan melakukan proses otentikasi pada semua portal dari masing-masing aplikasi. Dengan tolak ukur proses mengenali identitas pengguna terhadap aplikasi tujuan akan dilakukan berdasarkan berapa banyak aplikasi yang saling terhubung, secara garis besar digambarkan pada Gambar 4 (a), dengan 
menggunakan tiga aplikasi yaitu portal Central Authentication Service, FTP dan Web service (Wordpress) maka pada saat pengguna ingin mengakses, proses otentikasi akan dilakukan sebanyak tiga kali, sedangkan sistem yang telah terintegrasi Single Sign On akan melakukan otentikasi dan mengenali pengguna yang ingin mengakses tiga aplikasi dengan menggunakan satu akun seperti diilustrasikan pada Gambar 4 (b).

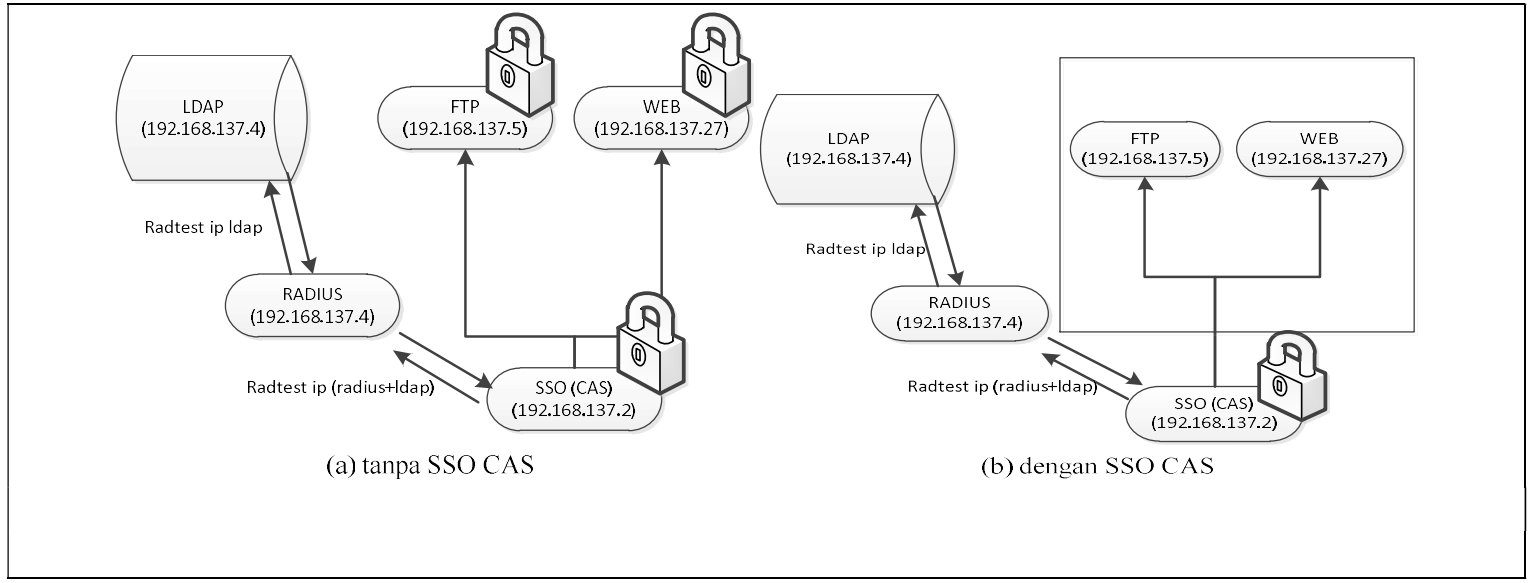

Gambar 4 Arsitektur tanda dan dengan Sistem SSO

\subsection{Topologi Pengujian}

Topologi pengujian untuk implementasi SSO pada Integrasi Explicite FTPS, RADIUS, dan LDAP untuk mencegah ancaman sniffing pada proses pertukaran dan penyimpanan data dapat dilihat pada Gambar 5.

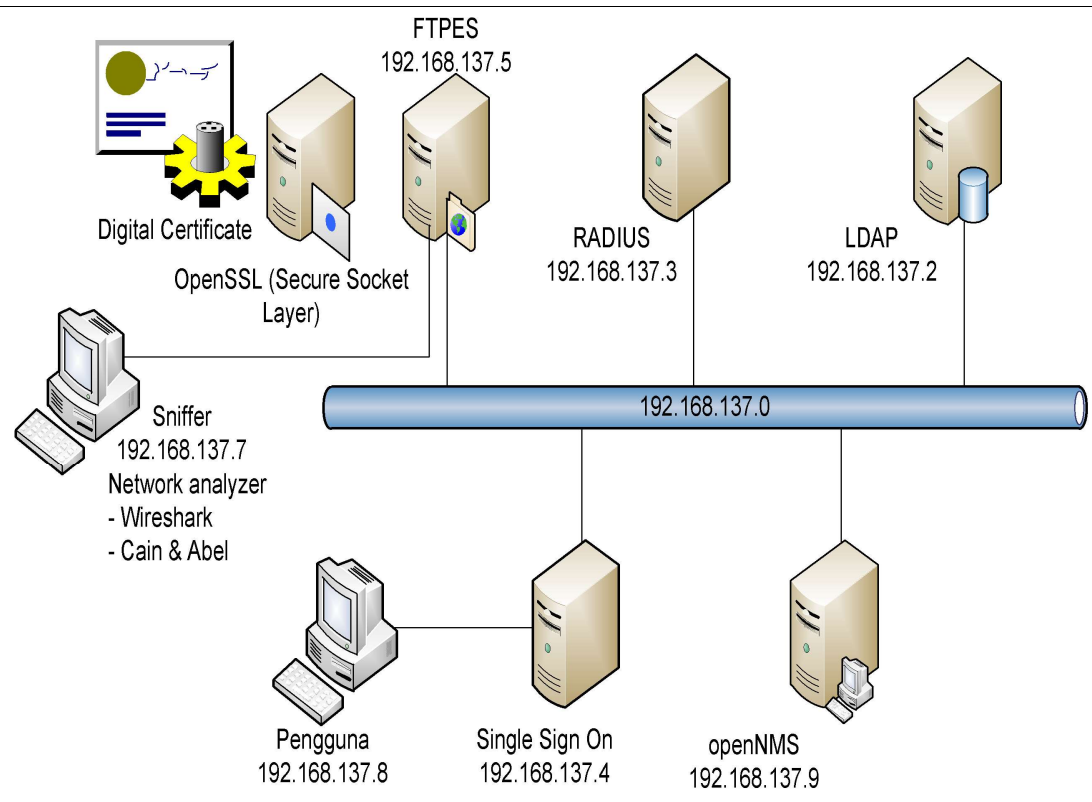

Gambar 5. Struktur dan Topologi

Pada Gambar 5 merupakan struktur topologi dimana sistem dimulai oleh pengaksesan data oleh klien dari satu komputer. Kemudian sistem aplikasi dihubungkan dengan server LDAP dan diintegrasikan dengan freeradius sebagai autentikasi. Sehingga jika klien ingin mengakases 
FTP server dengan autentikasi freeradius maka akan dihubungkan pada LDAP yang bertugas untuk manajemen pengguna, dimana pengguna dan passwordyang dimasukan oleh klien akan dibaca oleh server LDAP apakah sudah terdaftar di server LDAP, juga pada mail server untuk otentikasi dan manajemen pengguna akan dikelola oleh freeradius dan LDAP. Tugas untuk server adalah memonitor layanan server seperti LDAP, mail server dan ftp server layanan : up atau down, menampilkan trafik, dan memberikan informasi sistem yang berjalan.

Pada Gambar 6 merupakan diagram alir pada proses otentikasi SSO pada layanan explicite FTPS. Metode otentikasi secara terpusat pada direktori LDAP adalah melakukan pengecekan kecocokan akun tersebut yang akan menjadi parameter dari otentikasi izin akses dari RADIUS server.

Pada Gambar 7 menjelaskan komunikasi explicite FTPS dengan RADIUS dimulai dari permintaan koneksi dari pengguna. Jika explicite FTPS terkoneksi dengan RADIUS maka dilakukan proses otentikasi dilakukan, jika berhasil hak ases diberikan jika tidak proses akan dikembalikan ke proses permintaan akun.

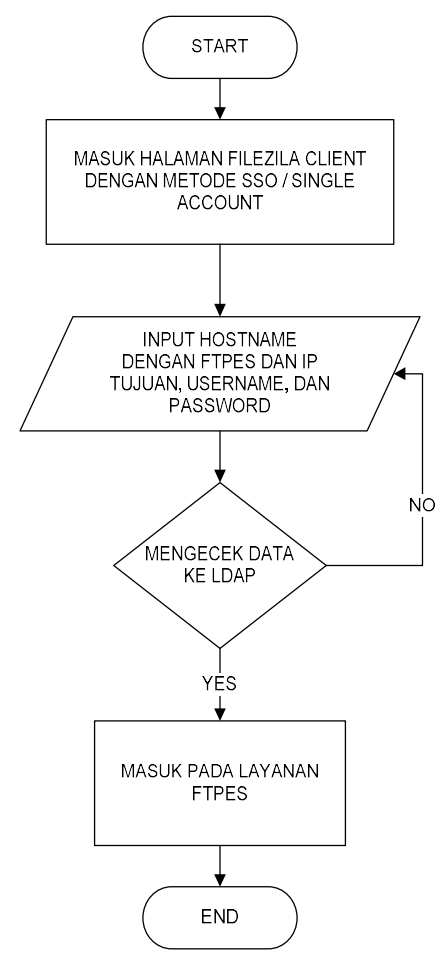

Gambar 6. Proses SSO terhadap layanan explicite FTPS 


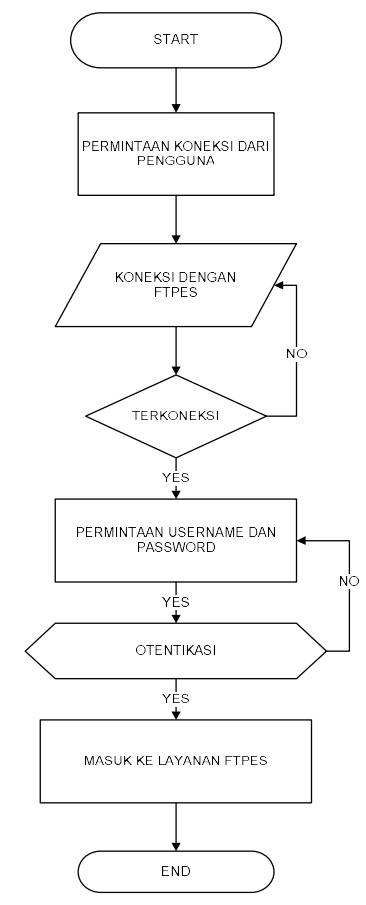

\section{Gambar 7. Komunikasi Explicite FTPS dengan RADIUS server}

Pada Gambar 8 menjelaskan diagram alir dari komunikasi RADIUS ke LDAP dengan parameter access reject atau access accept. Jika proses otentikasi dari metode SSO telah dilakukan maka akun tidak langsung digunakan untuk mengakses, melainkan diperiksa oleh server RADIUS apakah akun yang digunakan sesuai dengan akun yang terdaftar pada direktori LDAP.

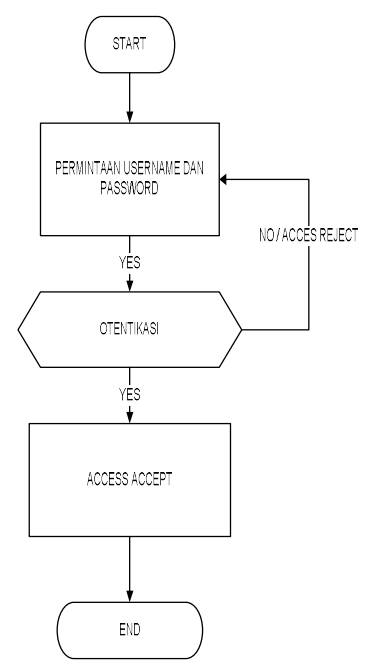

Gambar 8. Komunikasi RADIUS dan LDAP 


\subsection{Mekanisme SSO}

Cara melakukan login pada sistem SSO pada sistem yang banyak aplikasi yang sudah terintegrasi dapat dilihat pada Gambar 9. Sistem terdiri dari CAS dan LDAP sebagai server serta aplikasi explicite FTPS. CAS merupakan tempat ditanamkannya sistem SSO. CAS diintegrasikan dengan server LDAP yang merupakan tempat diletakkan basis data pengguna dari aplikasi berbasis explicite FTPS.

Proses kerja sistem SSO yang dibangun sebagai berikut:

1. Aplikasi berbasis Explicite FTPS diakses oleh pengguna

2. Pada saat berhasil login, pengguna diredirect browser menuju SSOServer.

3. Pengguna harus memasukkan username dan password untuk proses otentikasi.

4. Sistem mencocokan username dan password pengguna pada LDAP.

5. Setelah dilakukan pengecekan informasi, data pengguna dikirim kembali menuju server SSO.

6. Pengguna yang berhasil melewati proses otentikasi, diarahkan kembali ke aplikasi berbasis explicite FTPS dengan sebuah tiket.

7. Pengguna yang sudah sah dapat mengakses informasi yang terdapat pada aplikasi tersebut.

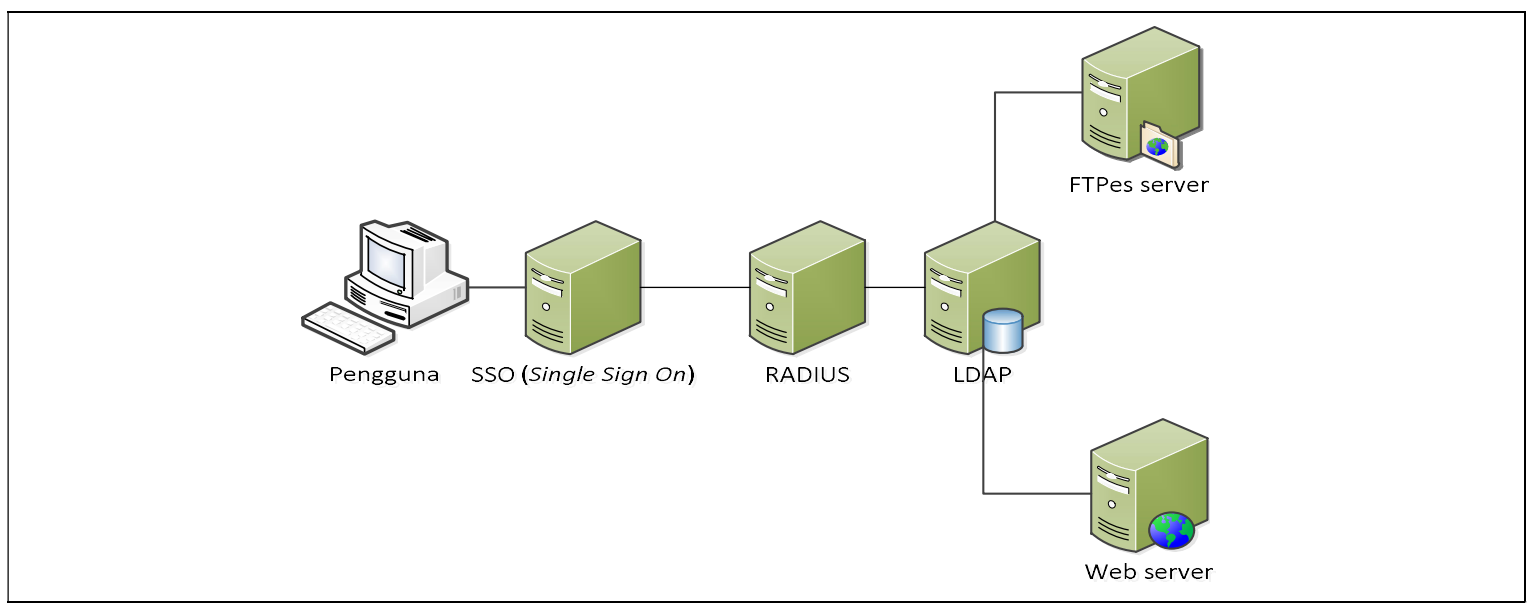

Gambar 9. Mekanisme SSO

\subsection{Mekanisme SSL}

Pada Gambar 10 menjelaskan teknologi SSL menggunakan konsep yang mirip dengan proses enkripsi pada kriptografi public, agar sistem komunikasi antara pengguna dan server menjadi aman. Pengguna dan server berinteraksi mengirimkan data dalam hal ini data disamarkan supaya tidak mudah terbaca dan untuk membacanya digunakan sandi dan kunci yang hanya dimiliki kedua pihak yang berkomunikasi tersebut, sehingga pihak lain yang mencoba menyadap data yang dikirim tersebut tidak akan bisa membacanya karena sandi dan kunci yang dibutuhkan tersebut hanya terdapat pada pihak yang melakukan komunikasi yaitu pengguna dan server. 


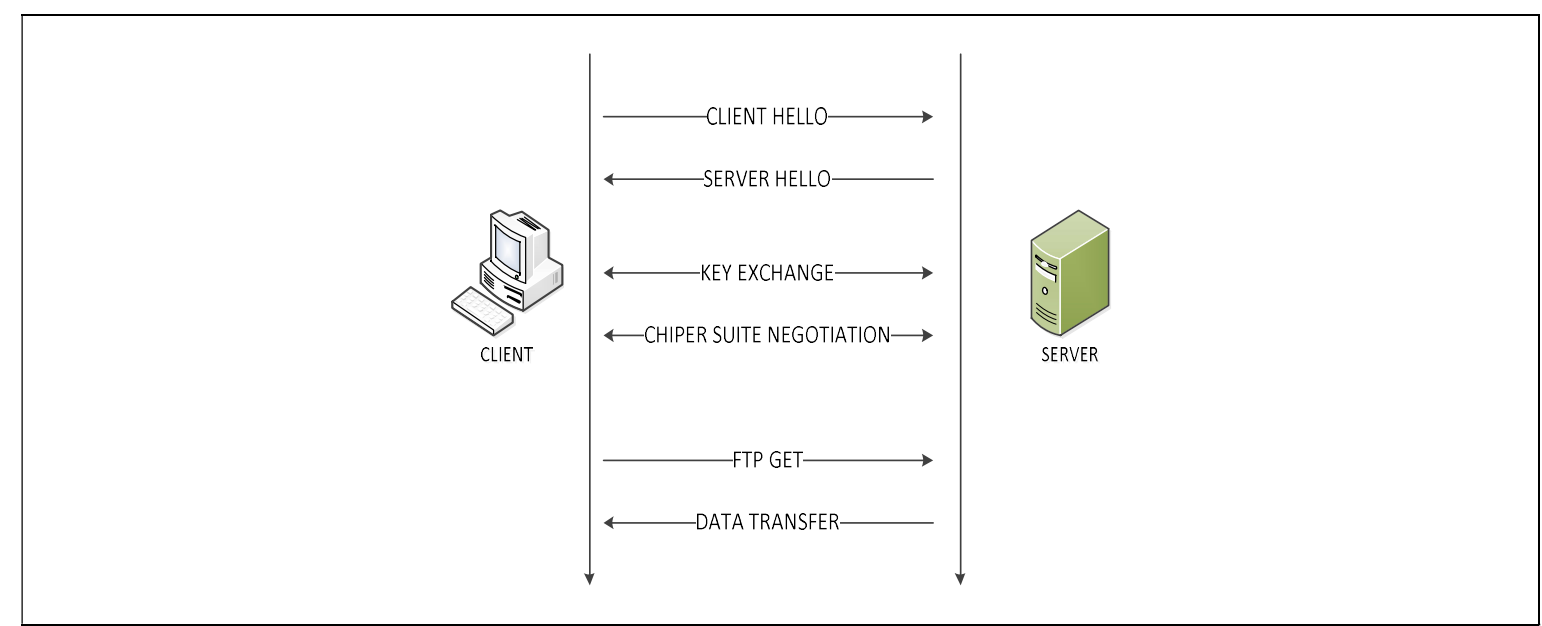

Gambar 10. Mekanisme SSL

\subsection{Mekanisme Explicite FTPS}

Pada Gambar 11 menjelaskan proses penerapan modul TLS sebagai dasar dari pembuatan sertifikasi digital, dengan memodifikasi layanan menjadi terfasilitasi oleh protokol kemanan dengan parameter Explicite secure dengan mengacu pada port 21/990. Dalam pengujian dengan aplikasi penganalisa jaringan packet data tidak dapat disadap dan akun pengguna dapat pengamanan saat proses otentikasi dilakukan. Parameter keberhasilan dari proses ini adalah jika module TLS dan SSL dapat diaktifkan maka authentication successful, jika module TLS dan SSL tidak dapat diaktifkan maka digital certificate dan authentication failed.

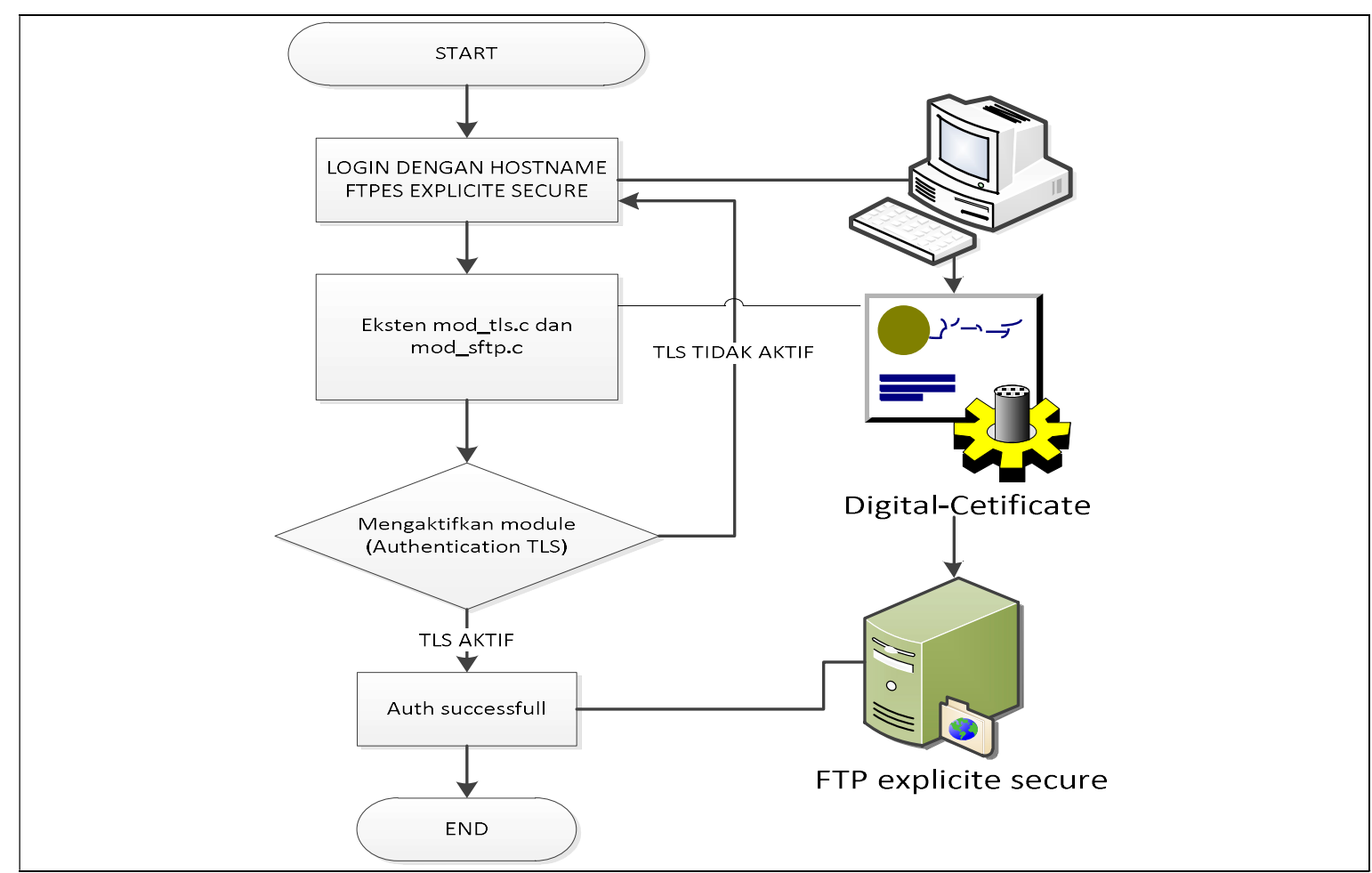

Gambar 11. Mekanisme Explicite FTPS 


\section{HASIL DAN PEMBAHASAN}

\subsection{Pengujian response time}

Pengujian response time dilakukan untuk memperoleh nilai waktu tanggap suatu sistem yang sedang terintegrasi ataupun tidak terintegrasi, dengan parameter pengujian dilakukan mulai saat proses otentikasi sampai informasi pada layanan dapat diakses.

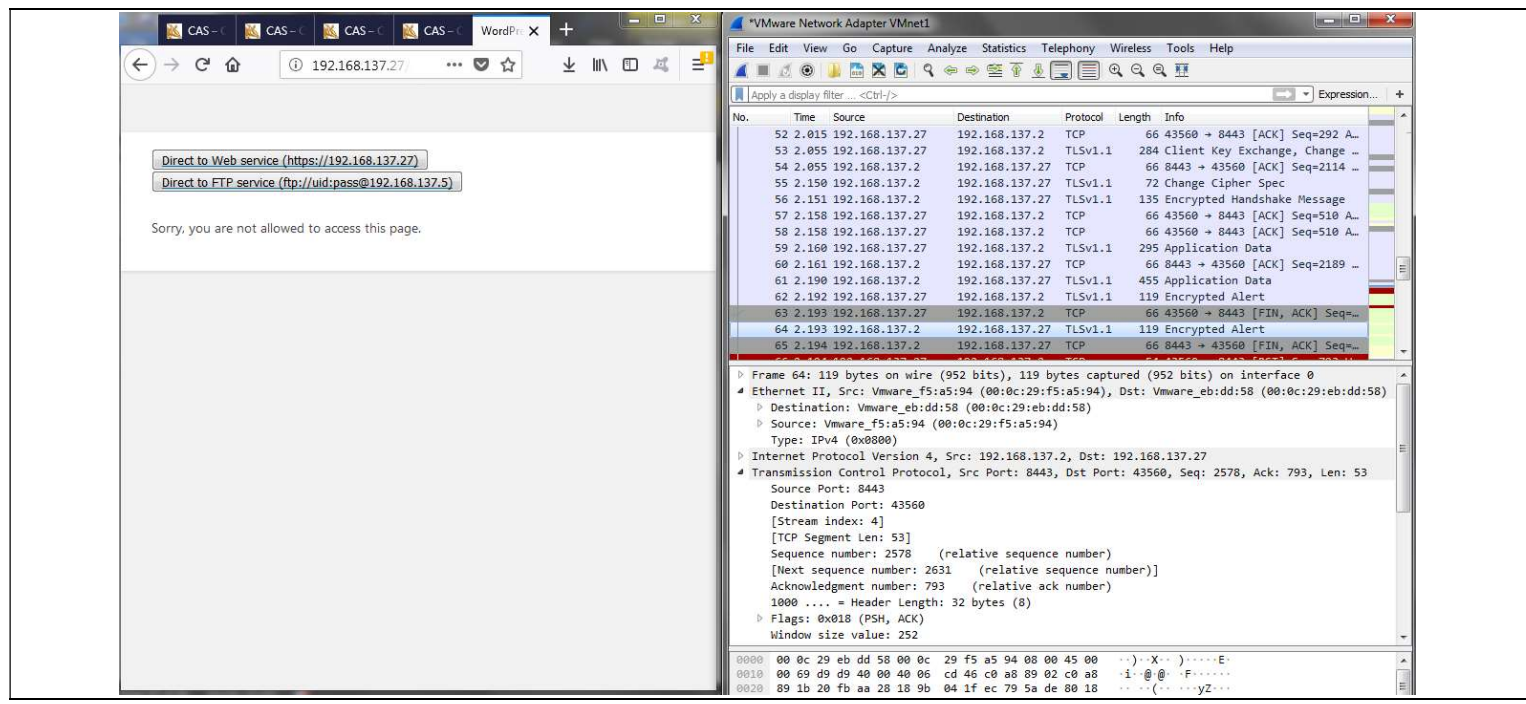

Gambar 12. Pengujian response time keseluruhan

Gambar 12. Pengujian analisis response time pada sistem keseluruhan mengambil parameter time dengan cara yang sama pada HTTPS karena SSO CAS menggunakan akses protokol yang sama dengan HTTPS.

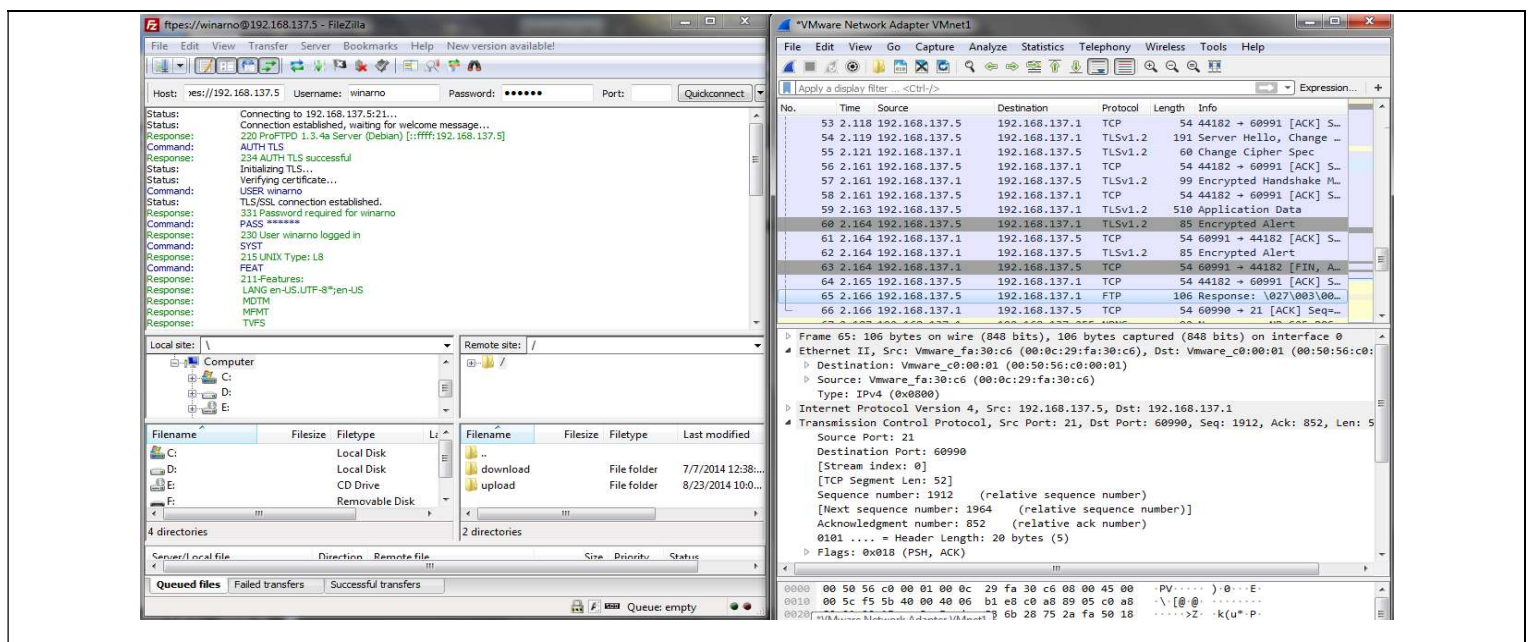

Gambar 13. Pengujian response time SSL pada FTP (FTPS)

Gambar 13. Pengujian analisis response time pada layanan dengan SSL pada FTP mengambil parameter time pada capture protocol TLS dari awal melakukan proses sampai pada batas akhir protocol TLS yang direkam. 


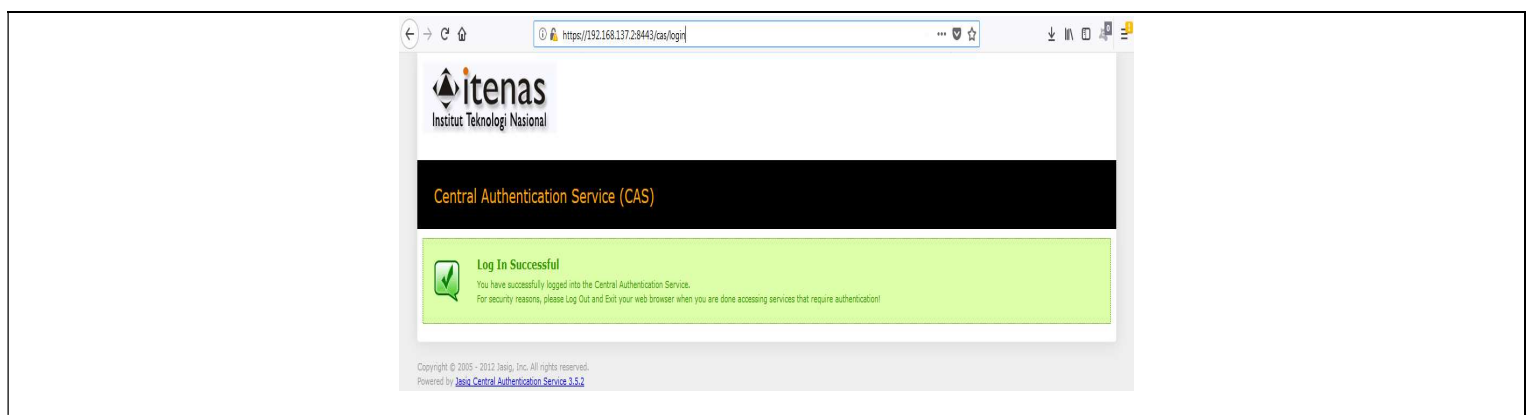

Gambar 14. Pengujian response time SSL pada HTTP (HTTPS)

Gambar 14. Pengujian analisis response time pada layanan dengan SSL pada HTTP mengambil parameter time dengan cara yang sama pada FTPES. Pengujian dilakukan 10 kali dengan browser, di setiap server. Waktu tanggap rata-rata adalah dihitung dengan menambahkan waktu respons keseluruhan dibagi dengan jumlah percobaan dilakukan.

\subsection{Pengujian tanpa dan dengan SSL}

Pengujian dengan metode sniffing bruteforce menggunakan hydra dapat dilihat pada Gambar 15, pengujian sniffing paket data yang dilakukan pada CLI linux dengan menggunakan hydra, dimana pada hasil pengujian diperoleh informasi uid dan password untuk layanan tanpa SSL. Sedangkan pada Gambar 16 merupakan pengujian yang dilakukan dengan menggunakan hydra pada kondisi layanan mengaktifkan modul SSL, dengan hasil status pengujian pada CLI linux dimana aplikasi hydra terpasang, tidak diperoleh informasi uid dan password yang digunakan oleh pengguna.

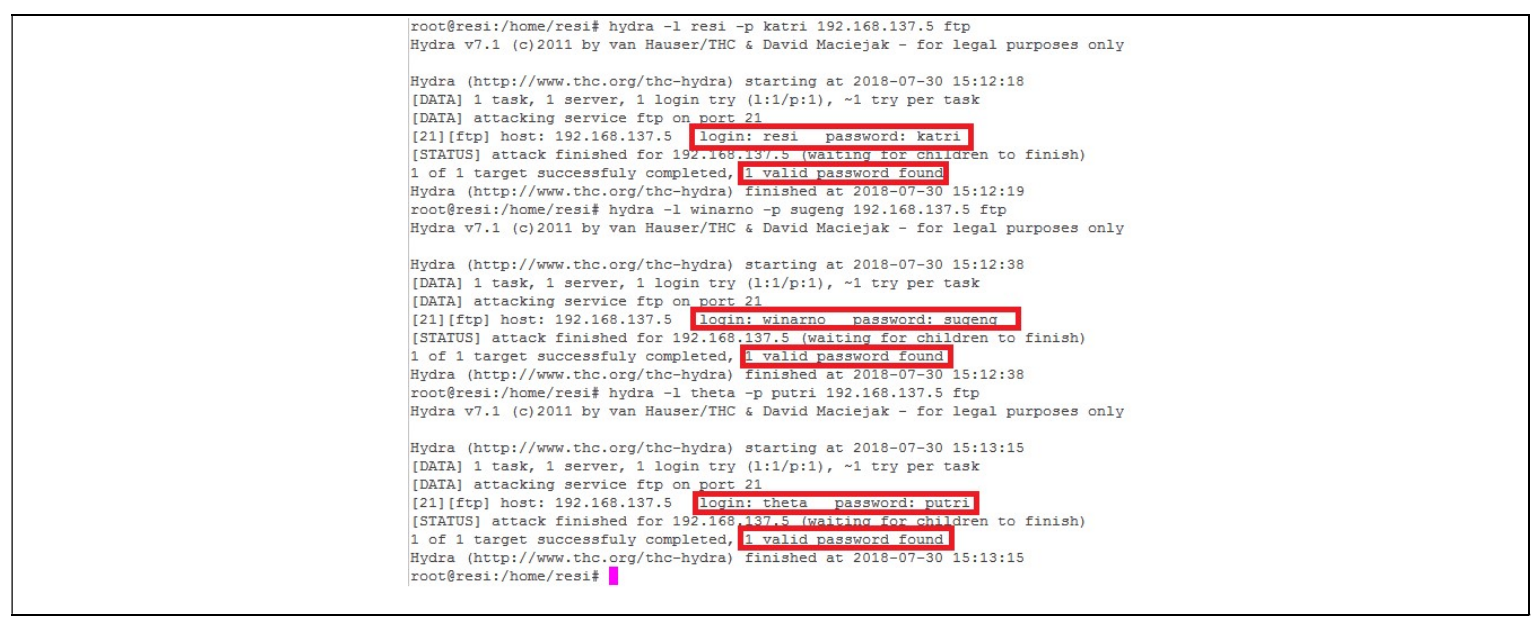

Gambar 15. Pengujian Hydra Layanan tanpa SSL

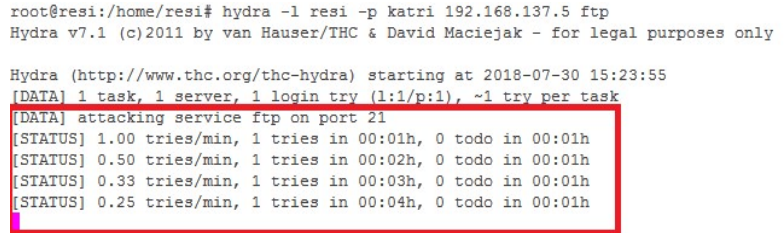

Gambar 16. Pengujian Hydra Layanan dengan SSL 


\subsection{Proses Sniffing menggunakan Wireshark}

Pengujian FTP tanpa protokol SSL Gambar 17 dilakukan dengan cara melakukan pengujian proses sniffing paket data pada layanan FTP tanpa SSL untuk mengetahui apakah username dan password terindentifikasi sebagai pengguna yang sedang mengakses suatu layanan pada saat pengujian proses capturing pada jaringan yang terhubung dengan pengguna wireshark disisi klien.

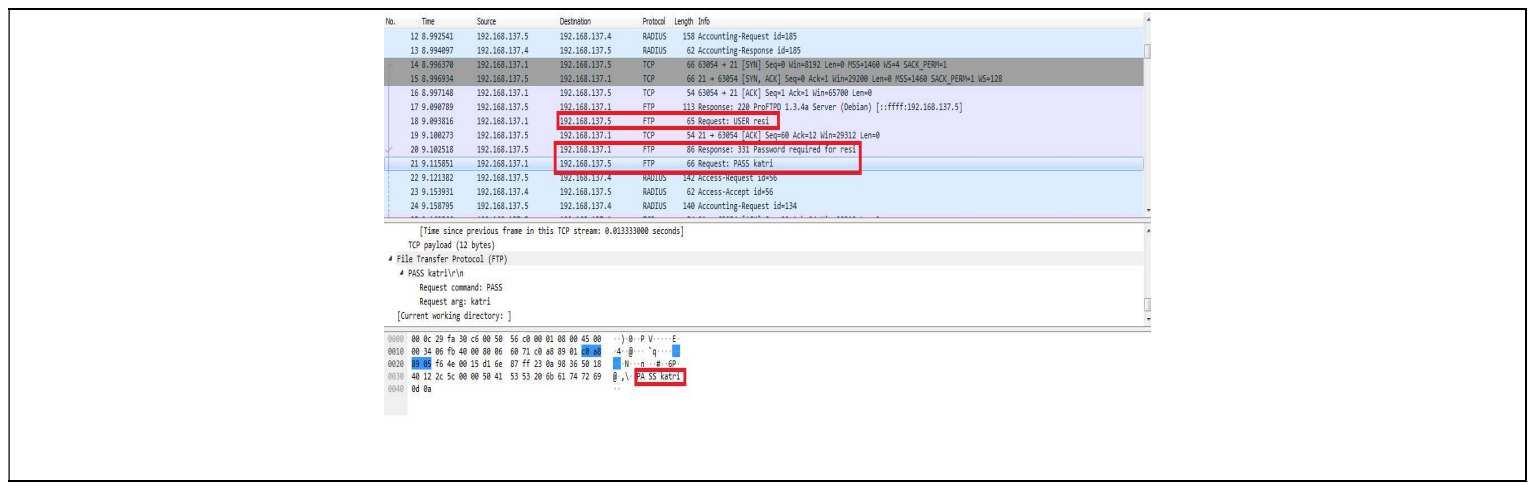

Gambar 17. Pengujian Jaringan FTP tanpa SSL

Pengujian FTP dengan protokol SSL (FTPES) Gambar 18 dilakukan dengan cara pengujian FTP dengan protokol SSL untuk megidentifikasi uid dan password sentralisasi ke basis data phpLDAPadmin, dengan hasil analisa jaringan FTPES username dan password tidak dapat ditemukan pada saat capture semua protokol yang sedang berjalan.

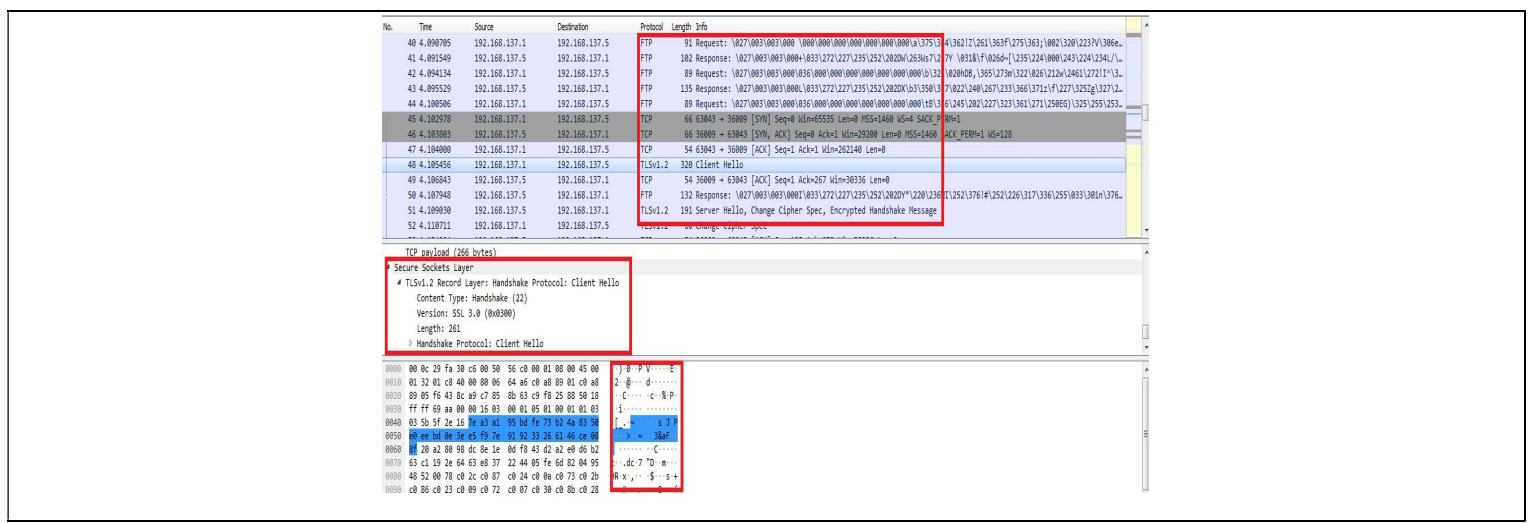

Gambar 18. Mengalisa Jaringan FTP dengan SSL

Pengujian RADIUS request-access accept pada layanan dengan protokol SSL Gambar 19 dilakukan pengujian pada proses perizinan access pada RADIUS, dimaksudkan menganalisa aktifitas jaringan pada pengembangan tahap satu dengan melakukan capture aktifitas jaringan RADIUS yang merupakan bagian dari integrasi sistem yang digunakan pada konsep SSO. Cara yang dilakukan dengan radtest (RADIUS testing) dengan meminta informasi uid dan password pada LDAP server. Hasil yang diperoleh dari capturing tidak terdapat informasi mengenai uid dan password dari RADIUS test ke LDAP server. 


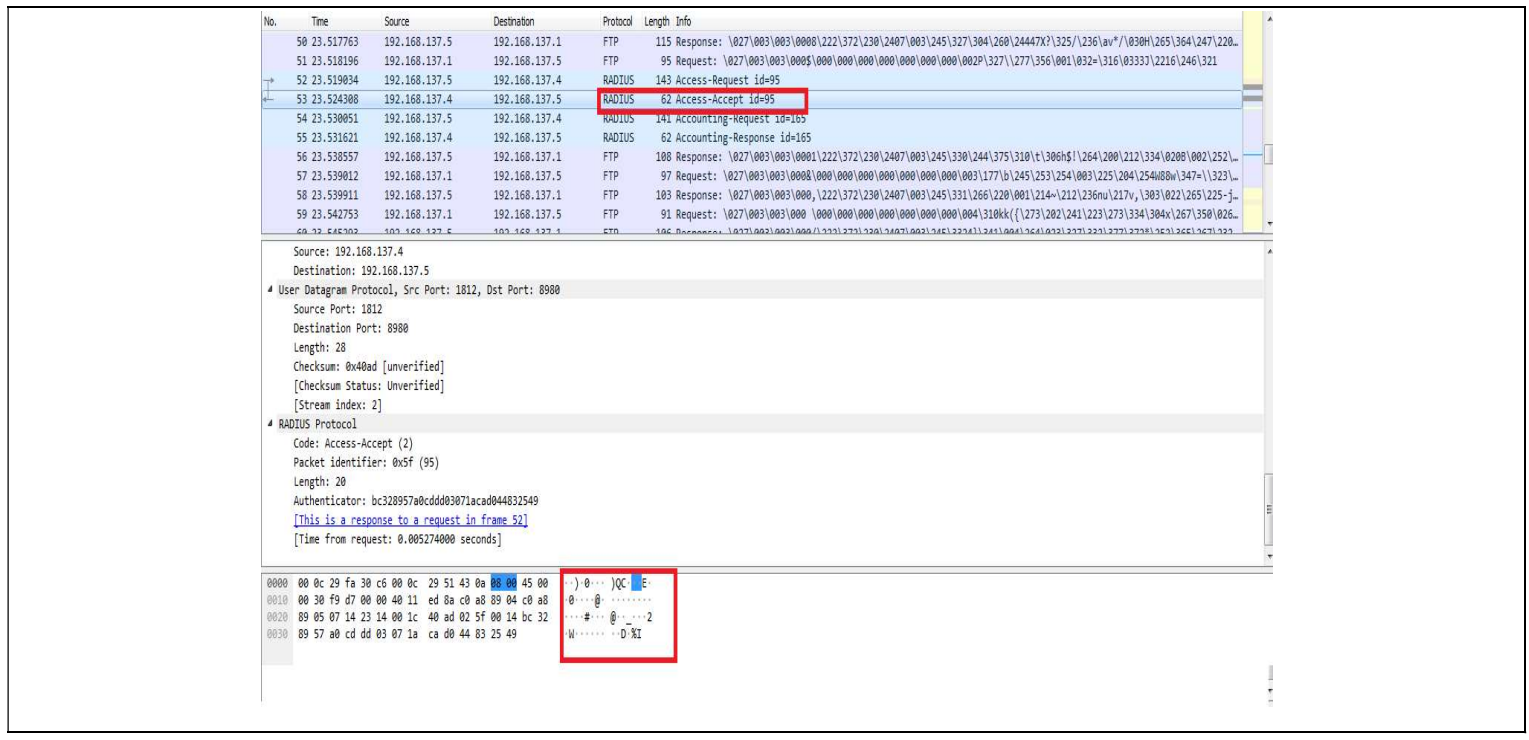

\section{Gambar 19. Pengujian Jaringan RADIUS}

Pengujian protokol HTTPS Gambar 20 pengujian menganalisa jaringan pada protokol HTTPS, dimaksudkan untuk menganalisa aktifitas jaringan Web service dengan protokol SSL. Dari hasil pengujian capturing tidak dapat diperoleh informasi uid dan password pada aktifitas jaringan pengembangan tahap satu untuk layanan web.

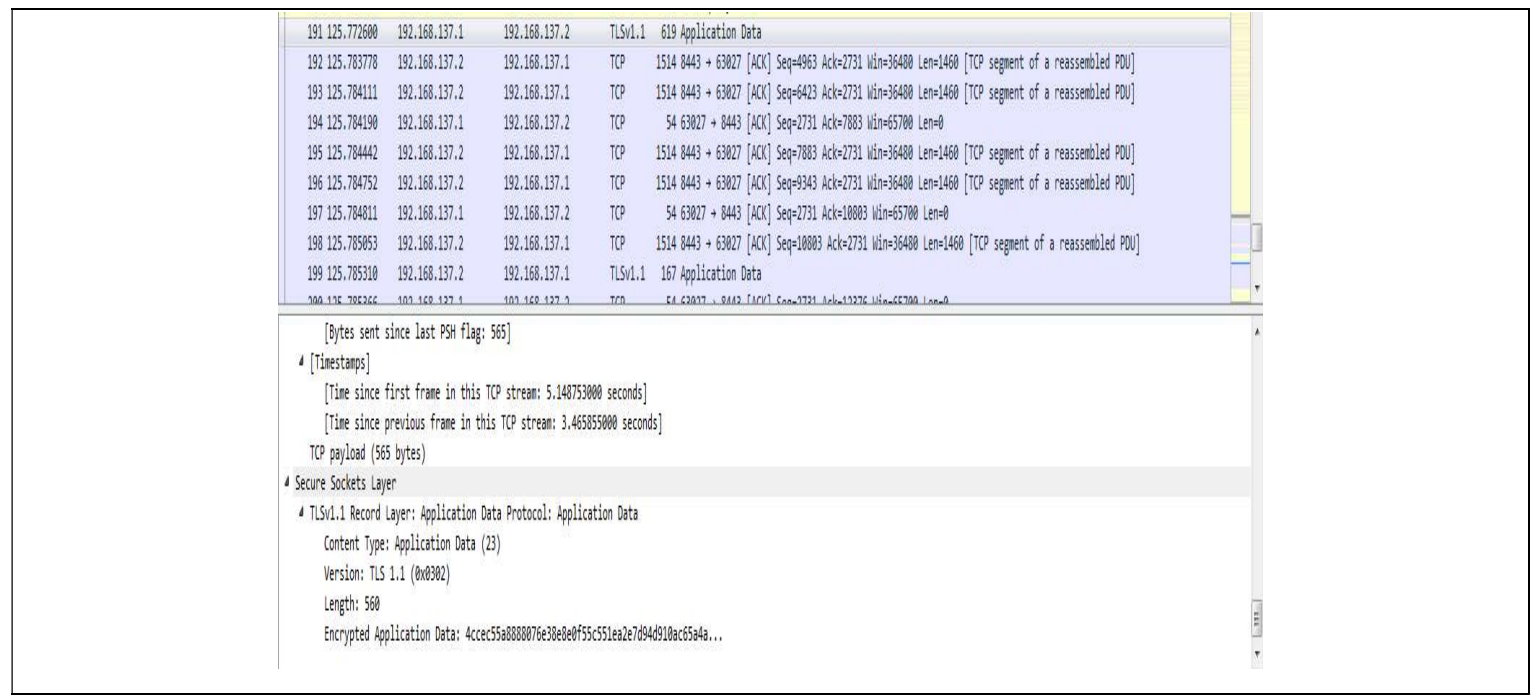

\section{Gambar 20. Pengujian Jaringan Web dengan Protokol SSL (HTTPS)}

Pengujian protokol HTTP Gambar 21 pengujian mengenalisa jaringan pada protokol HTTP, dimaksudkan untuk menganalisa aktifitas jaringan Web service tanpa protokol SSL. Dari hasil pengujian capturing dapat diperoleh informasi uid dan password pada aktifitas jaringan pengembangan tahap satu untuk layanan web. 


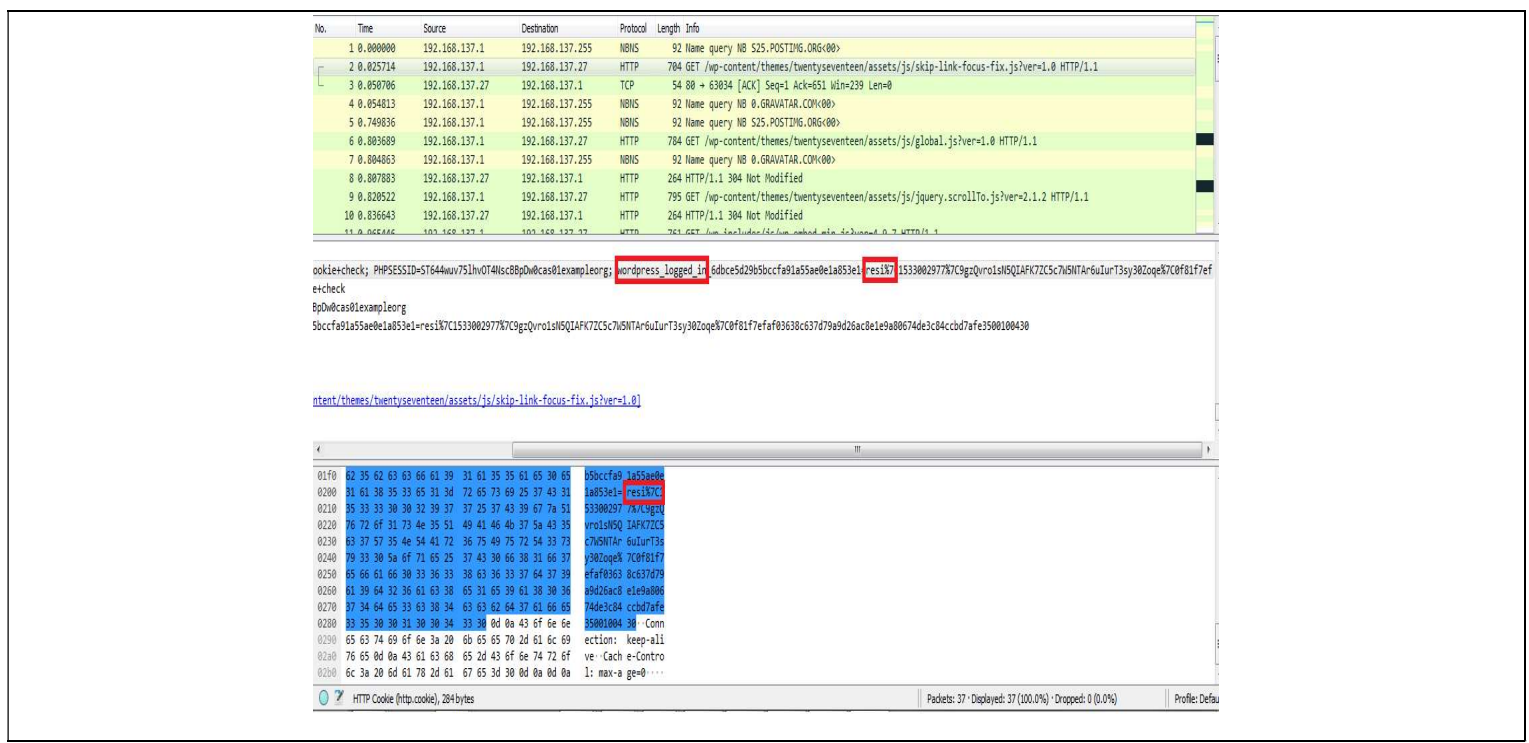

Gambar 21. Pengujian Jaringan Web tanpa Protokol SSL (HTTP)

\section{KESIMPULAN}

Sistem otentikasi login untuk mengakses banyak sistem dengan menerapkan konsep Single Sign-On metode Central Authentication Service pada dua layanan yaitu FTPES dan Web service terintegrasi RADIUS, dan LDAP, disimpulkan bahwa dengan metode tersebut proses menajemen dan otentikasi pengguna menjadi lebih efisien dan proses pertukaran data pada sebuah layanan data storage akan menjadi terproteksi.

Kesimpulan dari pengujian sistem keseluruhan berdasarkan konsep SSO CAS, jika konsep ini diterapkan pada dua layanan jaringan seperti FTP dan Web secara bersamaan maka waktu tanggap ( response time) pada proses otentikasi akan lebih lambat, tetapi dari segi penggunaan akun, aktifitas otentikasi dan otorisasi akan menjadi efisien dibandingkan tanpa menerapkan konsep SSO CAS, karena pada proses menganalisa dua aplikasi layanan jaringan akan melakukan proses capture dua kali, tergantung berapa jumlah aplikasi yang digunakan, sementara beberapa aplikasi dengan konsep SSO CAS proses capture aktifitas jaringan pada saat otentikasi dilakukan ke semua server yang terhubung diantaranya CAS, LDAP, RADIUS, FTP, Web, dan SSL. 


\section{DAFTAR RUJUKAN}

Agustian, A. F. (2013). Implementasi server RADIUS pada Cloud Computing berbasis GNU/Linux.

Aminuddin. (2014). Implementasi Single Sign On untuk Mendukung Interaktivitas Aplikasi ECommerce Menggunakan Protocol Oauth.

Amiruddin, A. (2018). Implementasi Security pada Load Balancing Layanan Web Multidomain dengan SSL.

D.C Pramudita, P. ,. (2014). Otentikasi dan Manajemen Pengguna Hotspot Router Mikrotik Menggunakan RADIUS dan PHP-MySQL.

Fernando, H. (2010). Studi dan Implementasi Sistem Keamanan Berbasis Web dengan Protokol SSL di Server Students Informatika ITB. Bandung: Program Studi Teknik Informatika Sekolah Teknik Elektro dan Informatika Institut Teknologi Bandung.

Juliharta, I. G. (2015). Bussiness Impact Analysis Aplikasi Jaringan Komputer dengan Teknik Packet Sniffing.

Prajna, I. K. (2014). Implementasi LDAP Server Integrasi Radius Auntetikasi Service dan Layanan OpenNMS sebagai Monitoring Server. Diambil kembali dari http://repository.taas.telkomuniversity.ac.id/index.php/Proyek-Akhir-

Mahasiswa/TK/Implementasi LDAP Server Integrasi RADIUS Autentikasi Service Dan Layanan OpenNMS Sebagai Monitoring Server

Rusmana, M. U. (2016). Sistem Monitoring Jaringan Menggunakan OpenNMS Berbasis Smartphone Android. 